
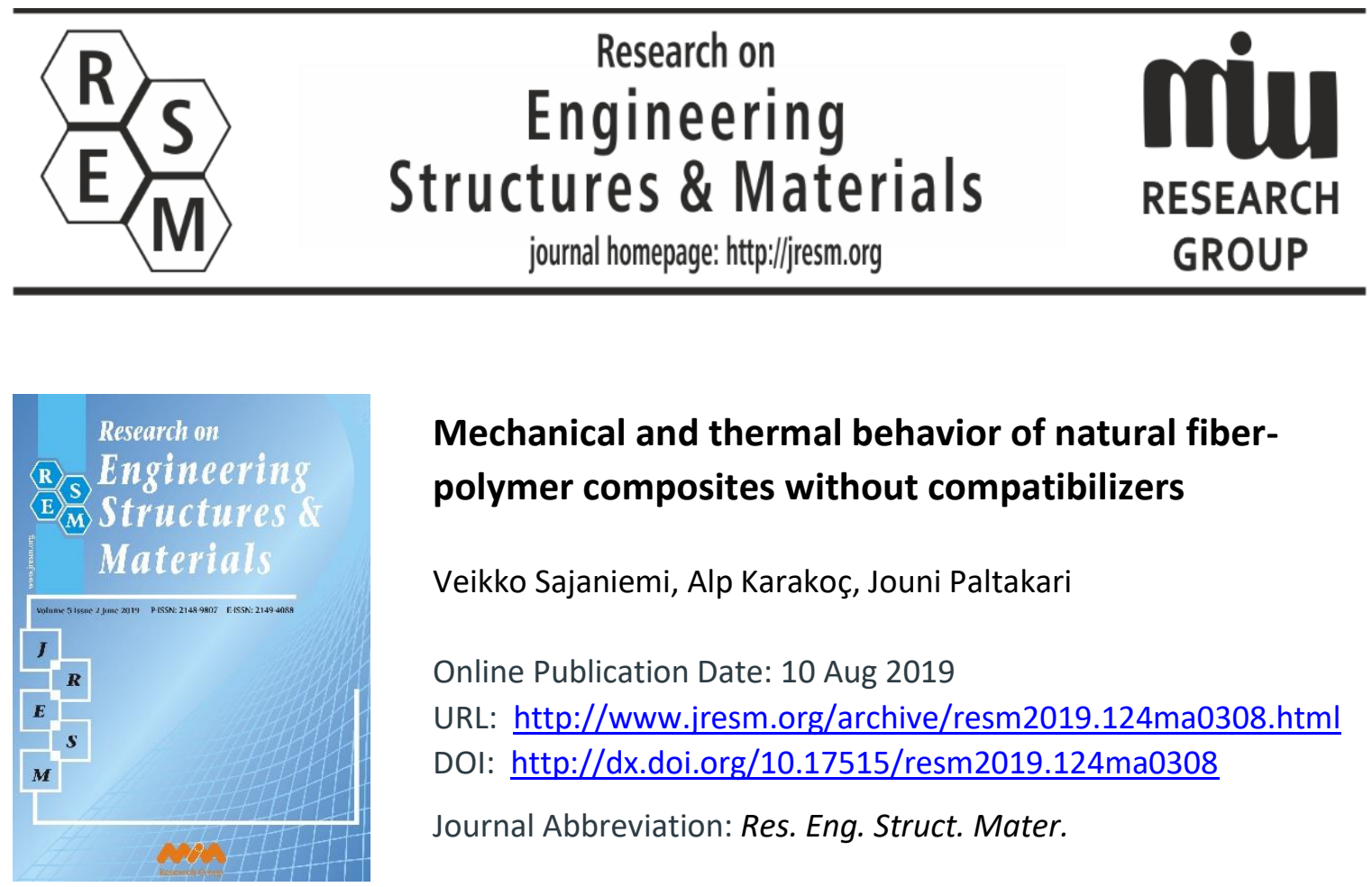

\title{
Mechanical and thermal behavior of natural fiber- polymer composites without compatibilizers
}

\author{
Veikko Sajaniemi, Alp Karakoç, Jouni Paltakari \\ Online Publication Date: 10 Aug 2019 \\ URL: http://www.jresm.org/archive/resm2019.124ma0308.html \\ DOI: http://dx.doi.org/10.17515/resm2019.124ma0308 \\ Journal Abbreviation: Res. Eng. Struct. Mater.
}

\section{To cite this article}

Sajaniemi V, Karakoç A, Paltakari J. Mechanical and thermal behavior of natural fiberpolymer composites without compatibilizers. Res. Eng. Struct. Mater., 2020; 6(1): 63-73.

\section{Disclaimer}

All the opinions and statements expressed in the papers are on the responsibility of author(s) and are not to be regarded as those of the journal of Research on Engineering Structures and Materials (RESM) organization or related parties. The publishers make no warranty, explicit or implied, or make any representation with respect to the contents of any article will be complete or accurate or up to date. The accuracy of any instructions, equations, or other information should be independently verified. The publisher and related parties shall not be liable for any loss, actions, claims, proceedings, demand or costs or damages whatsoever or howsoever caused arising directly or indirectly in connection with use of the information given in the journal or related means.

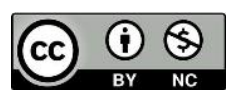

Published articles are freely available to users under the terms of Creative Commons Attribution - NonCommercial 4.0 International Public License, as currently displayed at here (the "CC BY - NC"). 


\title{
Research on Engineering Structures \& Materials
}

journal homepage: http://jresm.org

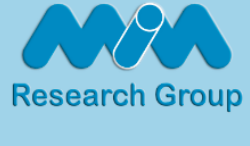

Research Article

\section{Mechanical and thermal behavior of natural fiber-polymer composites without compatibilizers}

\author{
Veikko Sajaniemia , Alp Karakoç*,b, Jouni Paltakaric,
}

Aalto University, Department of Bioproducts and Biosystems, P.O. Box 11000, FI-00076 Aalto, Finland

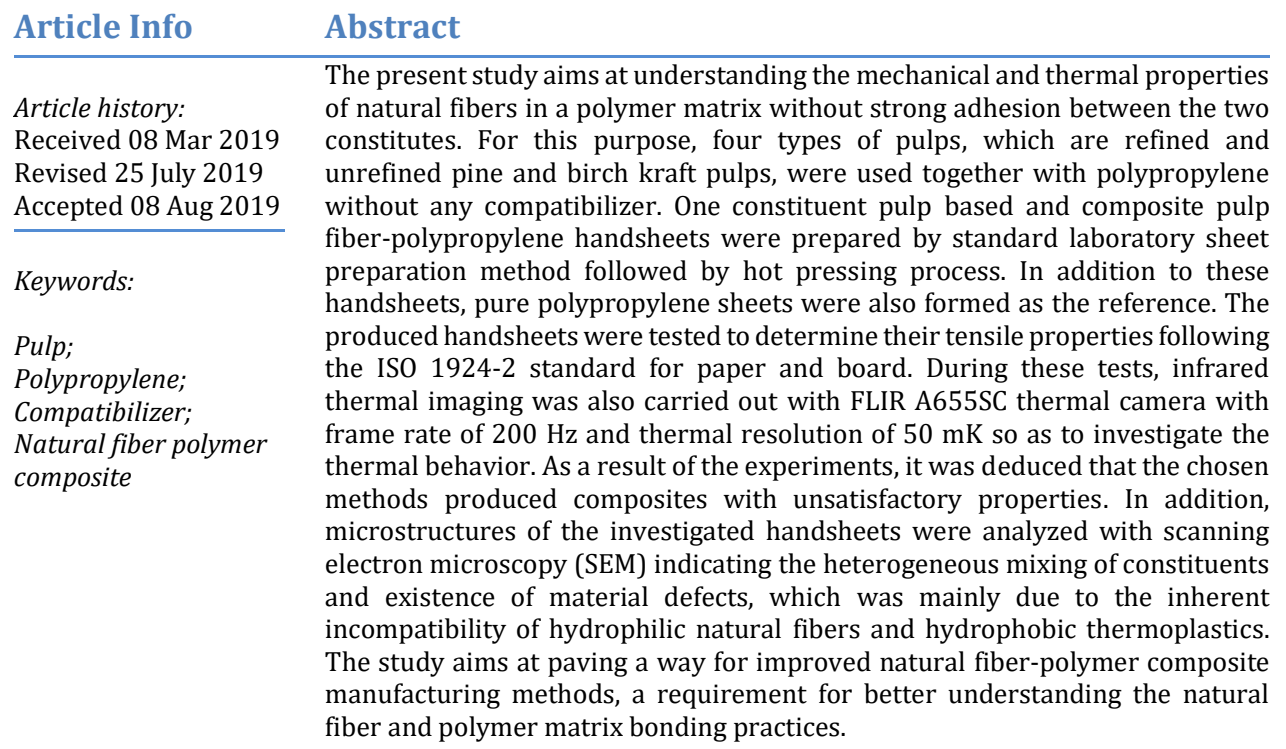

(C) 2019 MIM Research Group. All rights reserved.

\section{Introduction}

Since the natural fibers are abundant, ecological, economical, light and have high specific mechanical characteristics, they have been widely used as reinforcement in natural fiberpolymer composites with applications in paper and packaging, construction and automotive industries [1,2]. Thus, biocomposites based on natural fibers and especially thermoplastic polymer blends are being widely investigated to minimize the plastic waste problem [3-5]. The mechanical properties of these composites primarily depend on the elastic behavior and strength of fibers, fiber network, matrix and interfacial bonding [610]. Especially, a strong adhesion between the fiber and the matrix is of great importance for the effective load distribution and reinforcement throughout the composite [11-13]. However, in case of natural fiber-polymer composites, fibers are hydrophilic for most of the cases and incompatible with the common hydrophobic thermoplastics, which can limit the proper bonding $[14,15]$. Thus, various compatibilizers, such as phosphate titanite, or wood surface modification treatments, like acetylation, are used to bind the constituents together [16-18].

\footnotetext{
*Corresponding author: alp.karakoc@alumni.aalto.fi

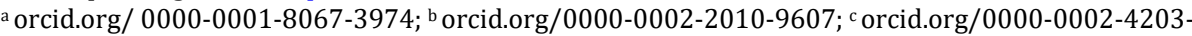
9814; 
In order to create an in-depth understanding of the bonding limits of natural fibers and thermoplastics, different natural fiber types with and without polymer matrix were investigated. For this purpose, four types of wood fiber; refined and unrefined birch kraft pulp and refined and unrefined pine kraft pulp; were investigated in polypropylene PP matrix without any compatibilizer. Mechanical properties of these composites were evaluated and compared to the papers made of either wood or PP that can be copolymerized to increase its strength and durability [19]. Thermal camera recordings were also used to understand the thermal characteristics of the investigated materials which were subjected to tensile loading. Therefore, the present study aims at providing an advancement in natural fiber-polymer composite design and manufacturing with findings on the effects of compatibilizers on the physical and mechanical characteristics of final products.

\section{Methodology}

As listed in Table 1, nine types of laboratory handsheets were formed out of four types of pulps by following the ISO 5269-1:2005 laboratory sheet preparation standard so as to conduct subsequent physical tests [20]. Sheets had a rectangular shape and a side-length of $16.5 \mathrm{~cm}$ and a grammage of $\sim 120 \mathrm{~g} / \mathrm{m}^{2}$. PP melting temperature was measured as 163 ${ }^{\circ} \mathrm{C}$ using hot plate and infrared thermometer in the Aalto University facilities. The measurements were in well alignment with the ones in the literature [21]. Composite handsheets were thereafter prepared adding PP granules to fiber-water suspension before forming process. Some adjustments, the details of which are elaborated below, were needed for these handsheets compared to the standard formation process due to the hydrophobic and light nature of the PP.

Based on the ISO-187:1990 standard atmosphere for conditioning and testing in line with ISO 5269-1:2005 laboratory handsheet preparation standard, the handsheets were kept in a room of $50 \%$ relative humidity and at $23^{\circ} \mathrm{C}$ temperature for minimum 24 hours for conditioning and drying $[20,22]$. Thereafter, the handsheets were hot pressed under steady conditions for 2 minutes at $180{ }^{\circ} \mathrm{C}$ temperature with $50 \mathrm{kN}$ force with Vakomet KRO-260 press and Siemens Simatic HMI KTP400 controller system. PP sheets of the same size and grammage as paper sheets were prepared by laying $3.267 \mathrm{~g}$ of PP granules in a paperboard frame, letting the specimen to melt on the hot press plate and pressing it to shape using $200 \mathrm{kN}$ force and $200{ }^{\circ} \mathrm{C}$ temperature.

Retention was determined at $95 \%$ and $94 \%$ with refined birch and pine, respectively. Unrefined pulps were assumed to have $100 \%$ retention due to non-existence of fines. PP retention was determined at $55 \%$, although it varied a lot due to challenging nature of PP granules in papermaking. PP had virtually no adhesion to fibers in aqueous phase and stuck easily to the walls of the handsheet trough. Also, PP interfered the process of removing fresh fiber mat from wire for drying. Being lighter than water and the fibers, PP granules settled on top of fiber matrix which resulted in very low adhesion of wet composite handsheets with the suction board. Additionally, PP granules detached easily out of the composite handsheets after drying the samples. Composite handsheets with unrefined pulps of low wet strength were especially challenging, the problem that was tackled adding part of the PP granules to dried handsheets just before the hot press. Due to these factors, the PP amount in these sheets varied profoundly. 
Table 1. Handsheet materials, identification, their fiber and polymer fractions, physical characteristics

\begin{tabular}{|c|c|c|c|c|c|}
\hline Material & ID & $\begin{array}{c}\text { Fiber } \\
\text { (mass \%) }\end{array}$ & $\begin{array}{c}\text { PP } \\
\text { (mass \%) }\end{array}$ & $\begin{array}{l}\text { Thickness } \\
(\mu \mathrm{m})\end{array}$ & $\begin{array}{c}\text { Grammage } \\
\left(\mathrm{g} / \mathrm{m}^{2}\right)\end{array}$ \\
\hline Birch, refined & $\mathrm{BR}$ & 100 & 0 & & \\
\hline Mean & & & & 169 & 122 \\
\hline Std. dev. & & & & $1 \%$ & $1 \%$ \\
\hline Birch, refined, with PP & BRPP & 50 & 50 & & \\
\hline Mean & & & & 302 & 122 \\
\hline Std. dev. & & & & $5 \%$ & $5 \%$ \\
\hline Birch, unrefined & BU & 100 & 0 & & \\
\hline Mean & & & & 253 & 126 \\
\hline Std. dev. & & & & $2 \%$ & $2 \%$ \\
\hline Birch, unrefined, with PP & BUPP & 50 & 50 & & \\
\hline Mean & & & & 279 & 121 \\
\hline Std. dev. & & & & $3 \%$ & $11 \%$ \\
\hline Pine, refined & PR & 100 & 0 & & \\
\hline Mean & & & & 190 & 124 \\
\hline Std. dev. & & & & $1 \%$ & $1 \%$ \\
\hline Pine, refined, with PP & PRPP & 50 & 50 & & \\
\hline Mean & & & & 244 & 127 \\
\hline Std. dev. & & & & $4 \%$ & $15 \%$ \\
\hline Pine, unrefined & PU & 100 & 0 & & \\
\hline Mean & & & & 268 & 118 \\
\hline Std. dev. & & & & $1 \%$ & $2 \%$ \\
\hline Pine, unrefined, with PP & PUPP & 50 & 50 & & \\
\hline Mean & & & & 317 & 127 \\
\hline Std. dev. & & & & $8 \%$ & $2 \%$ \\
\hline Polypropylene & PP & 0 & 100 & & \\
\hline Mean & & & & 244 & 127 \\
\hline Std. dev. & & & & $4 \%$ & $15 \%$ \\
\hline
\end{tabular}

Specimens were cut to dog-bone shape with mid-width of $10 \mathrm{~mm}$ and span length of 100 $\mathrm{mm}$ to determine their tensile properties by following the ISO 1924-2:2008 testing standard for paper and board [23]. Tensile tests were conducted under 50\% relative humidity and at $23^{\circ} \mathrm{C}$ temperature by using MTS $400 / \mathrm{M}$ vertical tensile testing system equipped with $200 \mathrm{~N}$ load cell. The cross-head speed was fixed to $12 \mathrm{~mm} / \mathrm{min}$ and the clamp span of $100 \mathrm{~mm}$ was used in these measurements. In this setup, displacement and strain readings were recorded via crosshead position while force and stress measurements were obtained through force transducer and the measure cross-sectional areas per specimen. Temperature difference at breakage point was determined using FLIR A655SC 
thermal camera with frame rate of $200 \mathrm{~Hz}$, optical resolution of $640 \times 480$ pixels and thermal resolution of $50 \mathrm{mK}$. The thermal images of the selected specimens can be found in the Appendix.

\section{Results and Discussions}

\subsection{Tensile properties and thermal characterization}

The tensile test results with mean and standard deviations are tabulated in Table 2 while the stress-strain curves are depicted in Figures 1 and 2 following the fiber content for birch and pine. Literature values for the elastic modulus of birch and pine based handsheets are between 1 and $10 \mathrm{GPa}$ depending on the fiber orientation [24,25]. In these one constituent handsheets, the fibers were randomly oriented and the handsheet elastic moduli obtained for the refined birch BR (4854 MPa) and the refined pine PR (4436 MPa) were well aligned with the previous investigations [26]. This was an expected outcome since the handsheets with one constituent have well established and standard production method. Nevertheless, in case of unrefined pulps, fiber bondings inside the handsheets were deduced to be weak since there was only mechanical and heat treatment for the formation process. Therefore, without the enhanced fiber bonding, interfiber breakage should prevail intrafiber failure, which results in lower elastic moduli as seen in unrefined birch and pine BU and PU, respectively, in Table 2. The same phenomenon explains the differences in tensile index, break strain and absorbed tensile energy. On the other hand, composite handsheets were deduced to have a lot of variation in their mechanical and thermal characteristics. This shows that importance of compatibilizers in composite handsheet formation, for which the bonding should be well built. Based on the present investigations, the compatibilizers are deduced to play a critical role especially in case of hydrophilic and hydrophobic constituents.
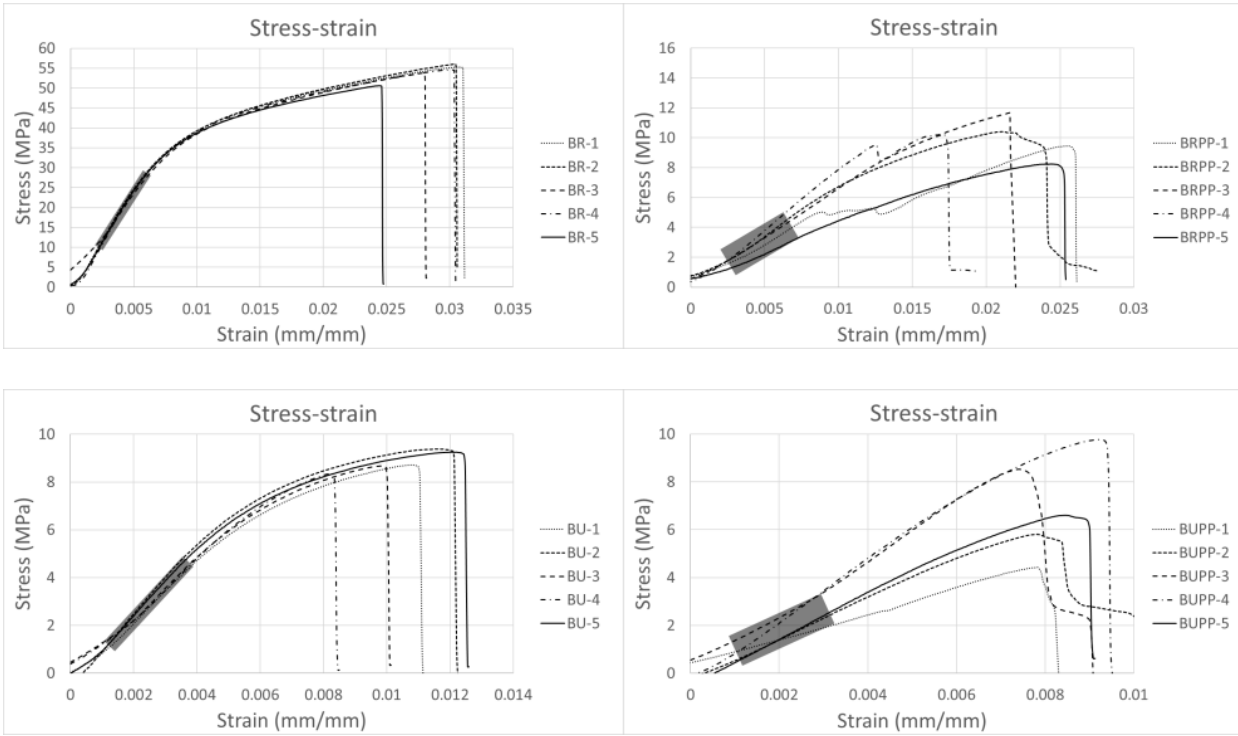

Fig. 1. Stress-strain curves obtained from tensile testing of handsheets from refined BR and unrefined birch BU and their blends with polypropylene PP. Highlighted domains represents the stress-strain ranges for the elastic modulus computations. 

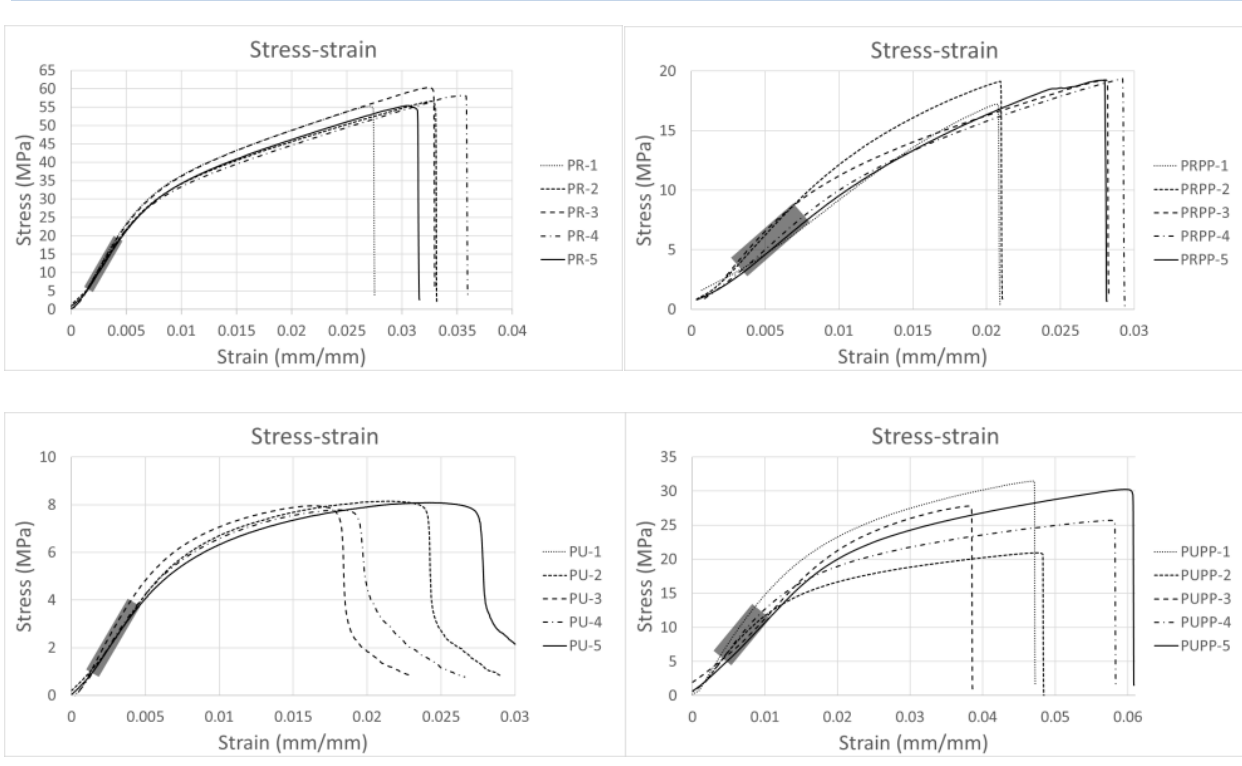

Fig. 2. Stress-strain curves obtained from tensile testing of handsheets from refined PR and unrefined pine PU and their blends with polypropylene PP. Highlighted domains represents the stress-strain ranges for the elastic modulus computations.

It is also observed that the produced composite handsheets did not follow the general rule of mixtures, i.e. neither Voigt model (upper-bound modulus) nor Reuss model (lowerbound modulus). This has been also observed by other researcher working on the natural fiber composites [11] when the fraction of pulp fibers in a PP matrix was over $20 \%$ by mass. For example, refined pulp-polymer composites BRPP and PRPP are significantly weaker than plain fiber or polymer sheets. On the other hand, the unrefined pulps seem to gain strength with the addition of polymer. The strength of these sheets primarily comes from the polymer phase as their grammage and fraction is much higher than those of the other composites due to modifications in the manufacturing method. The scanning electron microscopy (SEM) images in the following section support the postulate.

\subsection{Scanning electron microscopy}

In order to understand the details of the apparent properties of the handsheets, SEM images were recorded with Hitachi TM1000 tabletop microscope in charge-up reduction mode with acceleration voltage of $15 \mathrm{kV}$ recommended by the manufacturer. In contrast to the conventional sample preparation techniques, samples imaged by the TM-1000 required no special preparation such as metal coatings of non-conductive samples, which was very useful in terms of time and labor efficiency [27]. For the imaging, samples with surface areas of $2 \times 2 \mathrm{~mm}^{2}$ were cut from the handsheets, the thicknesses of which are same as the ones listed in Table 1. A wide range of magnifications from 100 to 2000 times was utilized to investigate the sample structure and constituents. The images presented in Figures 3-6 indicate the importance of the compatibilizers since the matrix and reinforcement were not mixed well enough to fulfil the reasonable mechanical characteristics. No polymer matrix is visibly present in between the fibers in the side and cross-section images of the refined birch-PP composite as shown in Figure 3. As also stated 
previously, this confirms the importance of the compatibilizers to bind matrix and fiber material together in natural fiber polymer composites.

Table 2. Tensile test results of different composite handsheets. Please, refer to Table 1 for the handsheet abbreviations BR, BRPP, BU, BUPP, PR, PRPP, PU, PUPP and PP.

\begin{tabular}{|c|c|c|c|c|c|}
\hline & $\begin{array}{c}\text { Elastic } \\
\text { modulus } \\
(\mathrm{MPa})\end{array}$ & $\begin{array}{l}\text { Tensile index } \\
(\mathrm{kNm} / \mathrm{kg})\end{array}$ & $\begin{array}{c}\text { Break } \\
\text { strain } \\
(\%) \\
\end{array}$ & $\begin{array}{c}\text { Tensile energy } \\
\text { absolute index } \\
\left(\mathrm{J} / \mathrm{m}^{2}\right)\end{array}$ & $\begin{array}{l}\mathrm{dT} \\
\left({ }^{\circ} \mathrm{C}\right) \\
\end{array}$ \\
\hline \multicolumn{6}{|l|}{ BR } \\
\hline Mean & 4854 & 75 & 2.8 & 1564 & 2.9 \\
\hline Std. dev. & $5.3 \%$ & $3.3 \%$ & $7.6 \%$ & $11 \%$ & $33 \%$ \\
\hline \multicolumn{6}{|l|}{ BRPP } \\
\hline Mean & 726 & 19 & 2.3 & 270 & 1.6 \\
\hline Std. dev. & $27 \%$ & $21 \%$ & $39 \%$ & $55 \%$ & $74 \%$ \\
\hline \multicolumn{6}{|l|}{ BU } \\
\hline Mean & 1161 & 18 & 1.0 & 117 & 2.6 \\
\hline Std. dev. & $9.8 \%$ & $4.3 \%$ & $13 \%$ & $21 \%$ & $9.4 \%$ \\
\hline \multicolumn{6}{|l|}{ BUPP } \\
\hline Mean & 1243 & 28 & 1.6 & 417 & 2.3 \\
\hline Std. dev. & $44 \%$ & $63 \%$ & $63 \%$ & $18 \%$ & $41 \%$ \\
\hline \multicolumn{6}{|l|}{ PR } \\
\hline Mean & 4436 & 87 & 3.0 & 1794 & 9.3 \\
\hline Std. dev. & $7.8 \%$ & $3.8 \%$ & $11 \%$ & $15 \%$ & $10 \%$ \\
\hline \multicolumn{6}{|l|}{ PRPP } \\
\hline Mean & 1295 & 44 & 2.2 & 597 & 4.5 \\
\hline Std. dev. & $17 \%$ & $5.1 \%$ & $21 \%$ & $26 \%$ & $31 \%$ \\
\hline \multicolumn{6}{|l|}{$\mathrm{PU}$} \\
\hline Mean & 975 & 18 & 1.8 & 243 & 1.1 \\
\hline Std. dev. & $9.7 \%$ & $1.4 \%$ & $18 \%$ & $21 \%$ & $18 \%$ \\
\hline \multicolumn{6}{|l|}{ PUPP } \\
\hline Mean & 1258 & 51 & 3.6 & 1415 & 3.0 \\
\hline Std. dev. & $22 \%$ & $25 \%$ & $47 \%$ & $63 \%$ & $49 \%$ \\
\hline \multicolumn{6}{|l|}{$\mathrm{PP}$} \\
\hline Mean & 1400 & 40 & 3.2 & 844 & 1.7 \\
\hline Std. dev. & $23 \%$ & $30 \%$ & $45 \%$ & $55 \%$ & $59 \%$ \\
\hline
\end{tabular}
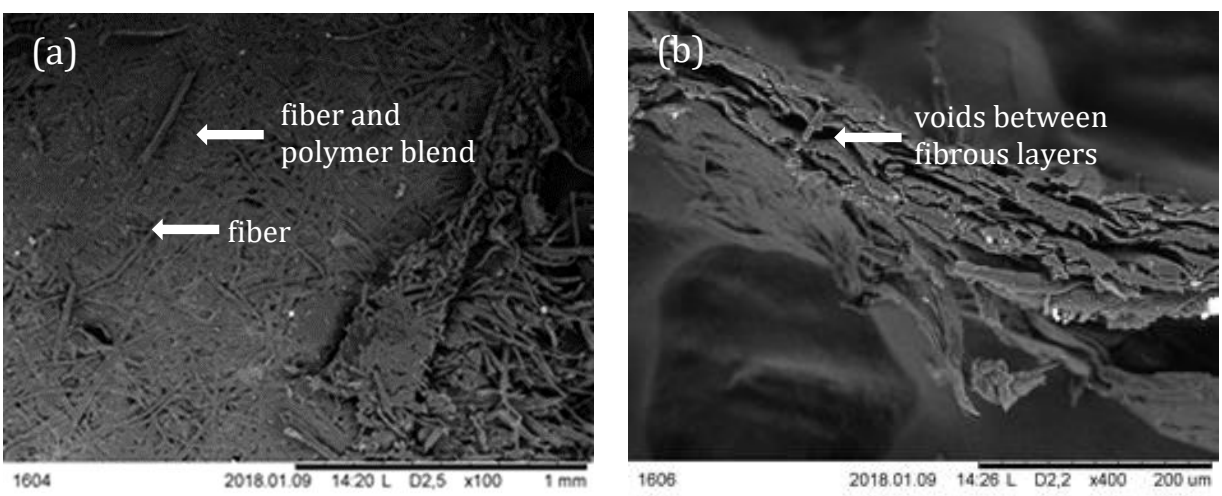

Fig. 3. SEM images of BRPP: (a) bottom side and (b) cross-section. 
The layered structure is even more evident with top and bottom images of BUPP depicted in Figure 4. Considering the increasing porous structure of unrefined pulp compared to refined one, it is very unlikely that any melted polymer could have penetrated the fiber network in the heat press for any of the investigated birch samples.
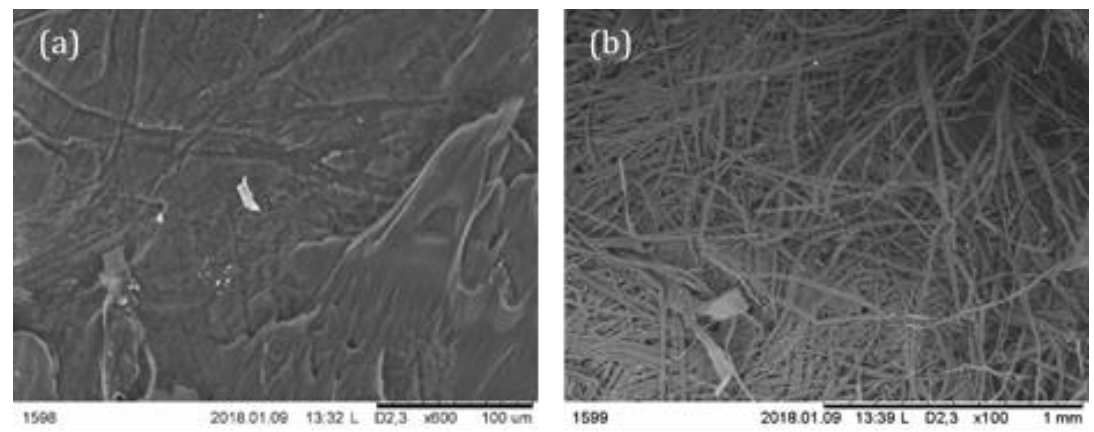

Fig. 4. SEM images of BUPP, (a) top side and (b) bottom side

Figures 5(a) and (b) show the layered structure of PRPP with a partially peeled off polymer coating on top of the fiber network. Through the thin polymer layer, the fiber network underneath is somewhat visible. The polymer layer contains pores in the magnitude of several tens of microns wide. These could be due to escaping water from the hydrophilic fibers during the hot pressing, though the sheets were thoroughly dried before the pressing. In addition to these, the cracks in Figures 5 (c) and (d) also indicate the brittle nature of polymer matrix resulting in poor and unstable mechanical properties.
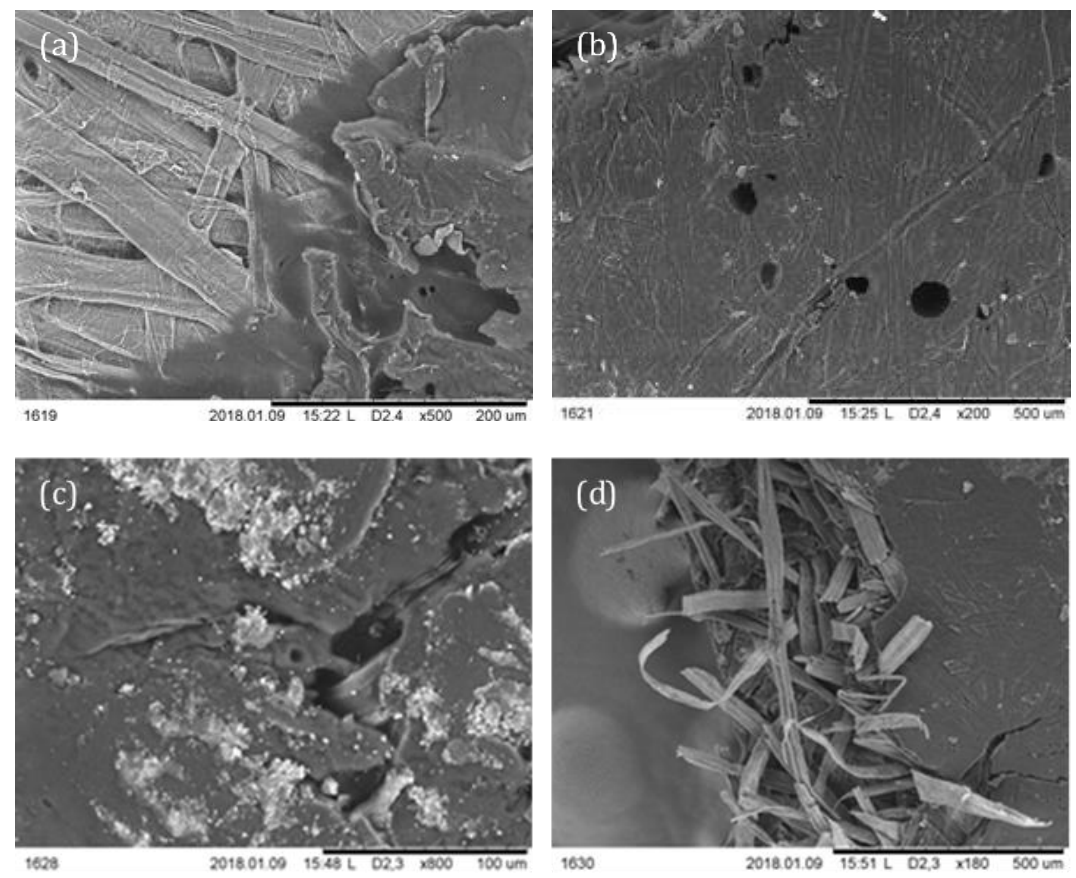

Fig. 5. SEM images of PRPP and PUPP, (a) PRPP image showing a peeled off layer of PP, (b) PRPP image showing pores in the matrix, (c) PUPP top side image, (d) PUPP cutting zone image 
Further study of the SEM images in Figure 6 shows uneven distribution of polymer structure within all the composite and plain polymer sheets. This shows the importance of standardization and urge for the development in the manufacturing method.
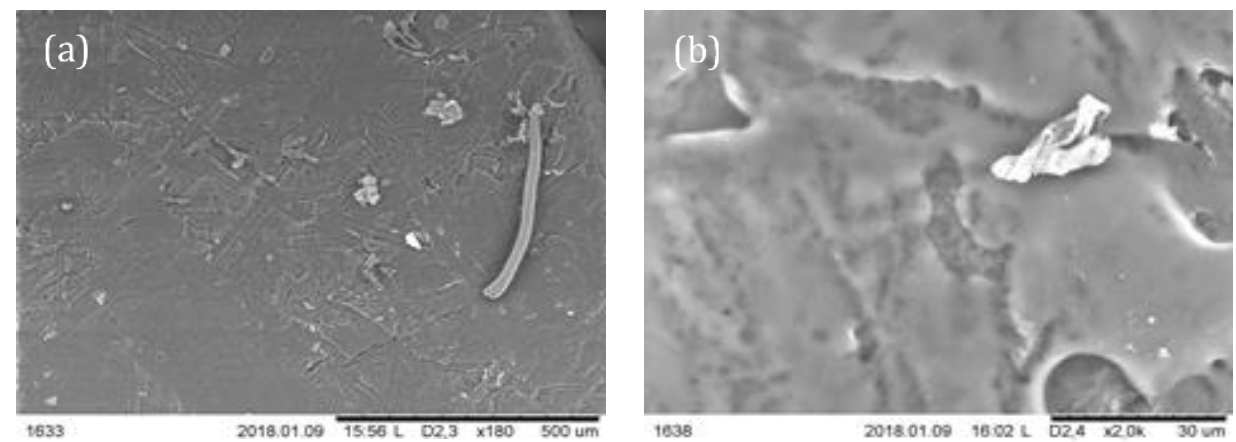

Fig. 6. SEM images of PP, with (a) 180x and (b) 2000x magnification

\section{Conclusion}

The present study was conducted to understand the effect of inherent incompatibility of hydrophilic natural fibers and hydrophobic thermoplastics on the mechanical and thermal behavior of their composites. Both the mechanical and thermal measurements exhibited a lot of variation and the chosen manufacturing method was deduced to produce unsatisfactory properties due to weak bonding between the constituents and existence of material defects such as pores, which can be clearly seen in the captured SEM images. This shows the necessity of compatibilizer use, which provides the retention and uniform mixing in case of constituent incompatibility.

Since the hot-pressing process was the mere option for the composite handsheet formation without damaging the fibers in the present facilities, another major challenge was the melting behavior of the PP during the process to get an interconnected and even matrix between the fibers. The hot pressing with the used parameters was not able to fulfil this task and fiber network was deduced to be dense for a uniform PP flow through. As seen in Figure 7(a), warping effect was experienced with most of the composite handsheets after hot pressing, which was an evidence of the nonuniform PP flow over the layered structure. When cutting the samples, the sheets had to be straightened as depicted in Figure $7(\mathrm{~b})$, which caused residual strains as the aftermath.
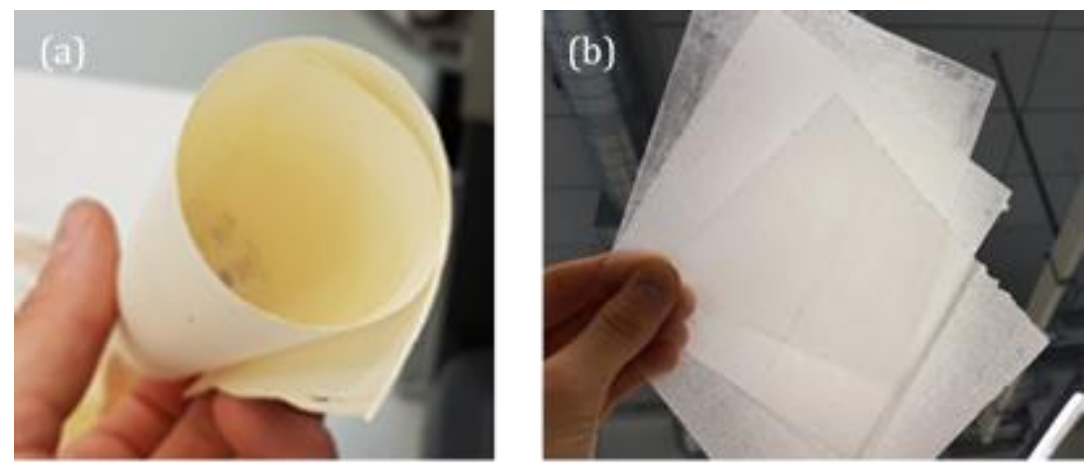

Fig. 7. Composite handsheets: (a) warping after hot pressing and conditioning to standard air moisture, and (b) handsheets to be used for test specimens 
All these manufacturing-based defects and constituent incompatibility were detrimental and resulted in low mechanical characteristics with high variations. Therefore, use of ply structure with low grammage and thin layers of fiber network with polymer stacked on top of each other in multiple layers could be a potential solution to this issue. In addition, increase in the pressure and process time would be also beneficial. Alternatives to hot pressing could also be considered, as long as the other methods do not damage the fibers. As a summary, the present study, which investigated the interactions between the reinforcement and the matrix without a compatibilizer, paved a way for improved natural fiber polymer composite manufacturing methods.

\section{References}

[1] Iorga L, Pan Y, Pelegri A. Numerical characterization of material elastic properties for random fiber composites. Mech Mater Struct 2008;3(7):1279-98. https://doi.org/10.2140/jomms.2008.3.1279

[2] Russell S. Handbook of nonwovens. Boca Raton, Florida, USA: The Textile Institute: Woodhead Publishing, CRC Press; 2007.

[3] Eszer NH, Ishak ZAM. Effect of compatibilizer on morphological, thermal and mechanical properties of Starch-Grafted-Polypropylene/Kenaf fibers composites. Materials Science and Engineering 2018; 368: 012017. https://doi.org/10.1088/1757899X/368/1/012017

[4] Özkan M, Karakoç A, Borghei M, Wiklund J, Rojas OJ, Paltakari J. Machine Learning assisted design of tailor-made nanocellulose films: A combination of experimental and computational studies. Polymer Composites 2019. https://doi.org/10.1002/pc.25262

[5] Özkan M, Borghei M, Karakoç A, Rojas O, Paltakari J. Films based on crosslinked TEMPOoxidized cellulose and predictive analysis via machine learning. Nature Scientific Reports 2018; 8 (4748): 1-9. https://doi.org/10.1038/s41598-018-23114-x

[6] Karakoç A. A fiber network model to understand the effects of fiber length and height on the deformation of fibrous materials. Research on Engineering Structures and Materials, 2016; 2(2): 51-57. https://doi.org/10.17515/resm2015.17ma0825

[7] Karakoç A, Hiltunen E, Paltakari J. Geometrical and spatial effects on fiber network $\begin{array}{llll}\text { connectivity. } \quad \text { Composite } \quad \text { Structures, 2017; } & \text { 168: }\end{array}$ https://doi.org/10.1016/j.compstruct.2017.02.062

[8] Lavrykov S, Lindström S, Singh K, Ramarao B. 3D network simulations of paper structure. Nordic Pulp Paper Research Journal 2012; 27(2): 256-263. https://doi.org/10.3183/npprj-2012-27-02-p256-263

[9] Sampson W. Modelling stochastic fibrous materials with Mathematica, London Springer-Verlag, 2009, ISBN: 978-1-84996-811-9.

[10] Targhagh M, Simulation of the mechanical behaviour of low density paper and an individual inter-fiber bond, MSc. Thesis, University of British Columbia, 2016.

[11] Poletto M, Zattera A. Mechanical and dynamic mechanical properties of polystyrene composites reinforced with cellulose fibers: coupling agent effect. Journal of Thermoplastic Composite Materials 2017; 30(9): 1242-1254. https://doi.org/10.1177/0892705715619967

[12] Yu L, Dean K, Li L. Polymer blends and composites from renewable resources. Prog. Polym. Sci. 2006; 31: 576-602. https://doi.org/10.1016/i.progpolymsci.2006.03.002

[13] Mydul MA, Ahmed T, Haque MM, Gafur MA, Kabir H. Mechanical properties of natural fibre containing polymer composites. Polym. Plast. Technol. 2009; 48: 10113.

[14] George J, Sreekala MS, Thomas S. A review on interfacial modification and characterization of natural fiber reinforced plastic composites. Polym. Eng. Sci. 2001; 41: 1471-1485. https://doi.org/10.1002/pen.10846 
[15] Pracella M, Minhaz-Ul Haque Md, Alvarez V. Functionalization, Compatibilization and Properties of Polyolefin Composites with Natural Fibres. Polymers 2010; 2(4): 554574. https://doi.org/10.3390/polym2040554

[16] Bledzki A, Gassan J, Theis S. Wood-filled thermoplastic composites. Mechanics of composite materials 1998; 34(6): 563-568. https://doi.org/10.1007/BF02254666

[17] Bledzki A, Gassan J. Composites reinforced with cellulose based fibers. Progress in Polymer Science 1999; 24(2): 221-274. https://doi.org/10.1016/S00796700(98)00018-5

[18] Saheb D, Jog J. Natural fiber polymer composites: a review. Advances in Polymer Technology 1999; 18(4): 351-363. https://doi.org/10.1002/(SICI)10982329(199924)18:4<351::AID-ADV6>3.0.CO;2-X

[19] Whiteley KS, Heggs GT, Koch H, Mawer RL, Immel W. Polyolefins. Ullmann's Encyclopedia of Industrial Chemistry. Weinheim: Wiley-VCH.

[20] Pulps -- Preparation of laboratory sheets for physical testing -- Part 1: Conventional sheet-former method. ISO 5269-1:2005. Geneva, Switzerland: ISO.

[21] Maier C, Calafut, T. Polypropylene: The Definitive User's Guide and Databook. Elsevier Science 2013, ISBN: 978-1-884207-58-7.

[22] Paper, board and pulps -- Standard atmosphere for conditioning and testing and procedure for monitoring the atmosphere and conditioning of samples. ISO-187:1990. Geneva, Switzerland: ISO.

[23] Paper and board -- Determination of tensile properties -- Part 2: Constant rate of elongation method. ISO 1924-2:2008. Geneva, Switzerland: ISO.

[24] Karakoç A, Tukiainen P, Freund J, Hughes M. Experiments on the effective compliance in the radial-tangential plane of Norway spruce. Composite Structures 2013; 102: 287293. https://doi.org/10.1016/i.compstruct.2013.03.013

[25] Gibson L. The hierarchical structure and mechanics of plant materials. Journal of the Royal Society, Interface 2012; 76(9): 2749-2766. https://doi.org/10.1098/rsif.2012.0341

[26] Berglund L, Carlsson L, Coffin D. Mechanics of Paper Products. Berlin, Boston DeGruyter, 2011, ISBN: 978-3-11-025463-1.

[27] Hitachi TM-1000 Tabletop Microscope Manual, http://www.marinereef.com/pdfs/tm-1000.pdf. Accessed 24 July 2019. 


\section{Appendix}

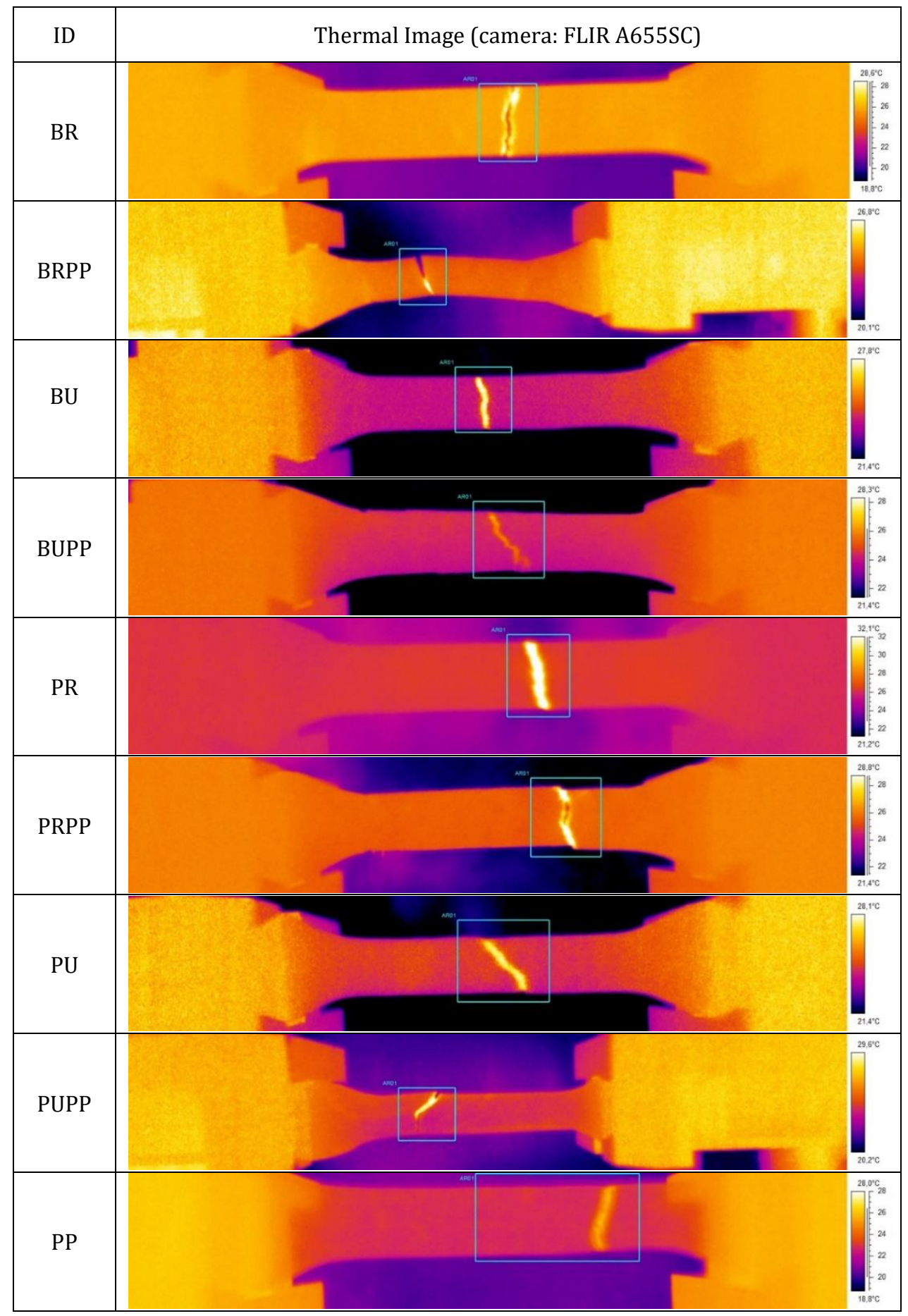

